\begin{tabular}{l} 
SCIENCE \& TECHNOLOGY \\
Journal homepage: http://www.pertanika.upm.edu.my/ \\
\hline PERTANIKA
\end{tabular}

\title{
Synthesis of Magnetic Activated Carbon Treated with Sodium Dodecyl Sulphate
}

\author{
Palsan Sannasi Abdullah*, Huda Awang and Jayanthi Barasarathi \\ Faculty of Agro Based Industry, Universiti Malaysia Kelantan Jeli Campus, 17600 Jeli, Kelantan, Malaysia
}

\begin{abstract}
Magnetic activated carbon (MAC) is found to be effective for the adsorption of methylene blue due to its physico-chemical properties such as strong adsorption of magnetization. The use of activated carbon (AC) for methylene blue adsorption was ineffective compared to MAC. MAC was prepared by incorporating different types of iron powder and chemicals [sodium dodecyl sulphate (SDS), citric acid (CA), dimethicone (D350), and epichlorohydrin $\left.\left(\mathrm{C}_{3} \mathrm{H}_{5} \mathrm{ClO}\right)\right]$ to strengthen the magnetism and stabilize the MAC. The methylene blue test and iodine test were tested on different samples. Characterization test on physical and chemical properties was carried out using Scanning Electron Microscopy (SEM) and X-ray diffraction (XRD). The yield of MAC was higher because of the addition of magnetic particles. The incorporation of magnetic particles had been proven by the SEM and XRD analysis that showed the presence of iron compound. The performance study of the adsorbent sample showed that MAC_A3II presented better qualities with highest removal percentage ( $98.81 \%$ of removal) in methylene blue adsorption and low magnetic contact time that showed strong magnetism. MAC_A3II was prepared by incorporating iron powder and treated by using sodium dodecyl sulphate (SDS). Among all the adsorbent sample, MAC_B2III performed the weakest quality because the dye removal percentage was low, and the preparation process was complicated compared with others.
\end{abstract}

ARTICLE INFO

Article history:

Received: 27 September 2020

Accepted: 25 November 2020

Published: 22 January 2021

DOI: https://doi.org/10.47836/pjst.29.1.24

E-mail addresses:

palsan.abdullah@umk.edu.my (Palsan Sannasi Abdullah)

hudaawang@gmail.com (Huda Awang)

jayne_barath@yahoo.com (Jayanthi Barasarathi)

* Corresponding author
Keywords: Iron powder, magnetic activated carbon, methylene blue adsorption, sodium dodecyl sulphate

\section{INTRODUCTION}

Batik is a traditional fabric craft with handpainted and richly colored patterns. The batik industry is one of economic driven industries in east coast states of Malaysia- Kelantan and Terengganu (Jamaludin, 2020). Many 
batik entrepreneurs built their manufacturing units along the adjoining riverside for disposal of wastewater such as dyes, grease, wax, and heavy metals (Ramakreshnan et al., 2020). Methylene blue (MB) is commonly used dye in batik industry. The presence of dye in rivers not only deteriorates aesthetic value of water but also compromises human health (Ewadh, 2020). Thus, a proper treatment for effluents rich in color and organic pollutants is required prior to discharging into the environment (Ramakreshnan et al., 2020). One of the methods applied to treat the wastewater is Advanced Oxidation Processes (AOP). In this method, the spent bleaching earth impregnated with Tungsten trioxide went through sonocatalytic to form hydroxyl radicals. The hydroxyl radicals therefore destruct pollution compounds. Although the percentage of pollutant degradation is $99.12 \%$ the process is expensive for a small cottage batik manufacture (Hindryawati et al., 2020). Therefore, adsorption is an effective method to treat wastewater. Many industries used commercial AC to treat effluents from factories, the drawbacks of AC are high cost and disposal problem (Vyavahare et al., 2019). Thus, current research found the potential of agricultural waste to produce activated carbon. By this way, it is not only cost effective but also environment- friendly (Shokry et al., 2020). Furthermore, production on magnetic activated carbon (MAC) from agricultural waste represents novel adsorbent for water purification. Activated carbon is a high-content carbon enriched with minerals adsorbent. By this way, it is not only cost effective but also environment- friendly (Shokry et al., 2020) Activated carbon can be produced through the pyrolysis of biomass in the absence of oxygen at $\leq 500^{\circ} \mathrm{C}$ or carbonization process and it is a carbon rich residue. Activation step of activated carbon involved oxidizing gases such as steam, air, and carbon dioxide (Ooi et al., 2013). It has porous properties which can increase the removal of contaminants from aqueous solution. It also has large specific surface area and strong redox reactivity (Yao et al., 2015). Therefore, unique properties of activated carbon are widely used as a filter to improve the quality of water and wastewater whereby it increases efficiency of water treatment and reduces the spread of contamination from hazardous chemicals. Accordingly, MAC is proposed to improve effectiveness of separation process which aided by external magnetic field (Shokry et al., 2020). The key obstacle of impregnation process is magnetic particles does not fully impregnate with the AC. In order to encounter the problem, a surfactant is applied due to change the surface properties of adsorbent. The hydrophobic and hydrophilic characteristics of the surfactant enable improve adsorption capacity by affecting solubility of the organic pollutant. Thus, organic pollutants such as dye is suggested to test the performance of impregnation process with surfactant treatment ( $\mathrm{Li}$ et al., 2019). An alternative method to produce magnetic activated carbon derived from coconut shell with sodium dodecyl sulfate treatment is proposed in this study. Besides, the methylene blue will be used as pollutant to test the adsorbent. The challenge of this study is to show that MAC is a competitive adsorbent by comparing with commercial AC. Hence, the objective of this study was to synthesis magnetic activated carbon treated with SDS and to test the performance of the novel adsorbent. 


\section{MATERIALS AND METHOD}

\section{Chemical and Reagents}

The chemical and reagent used in the research were hydrochloric acid, $\mathrm{HCl}(37 \%)$, ammonium hydroxide, $\mathrm{NH}_{4} \mathrm{OH}(28 \%), 2 \mathrm{M}$ hydrochloric acid, $\mathrm{HCl}(2 \mathrm{M})$, ammonium hydroxide, $\mathrm{NH}_{4} \mathrm{OH}(0.7 \mathrm{M})$, iodine solution $(0.1 \mathrm{~N})$, sodium thiosulphate solution, $\mathrm{Na}_{2} \mathrm{~S}_{2} \mathrm{O}_{3}$ $(0.05 \mathrm{~N})$, starch solution, sodium carbonate, $\mathrm{Na}_{2} \mathrm{CO}_{3}$, potassium iodide $(\mathrm{KI})$, and distilled water. The magnetization of $\mathrm{AC}$ was carried out using iron powder (IFP) and labelled as Group A; Group B was $\gamma-\mathrm{Fe}_{2} \mathrm{O}_{3}$ (I30B), the gamma phase of ferrous oxide; Group $\mathrm{C}$ was $\alpha-\mathrm{Fe}_{2} \mathrm{O}_{3}$ (I30) the alpha phase of ferrous oxide; Group D was ferrous chloride, $\mathrm{FeCl}_{2}$ impregnated with ferric chloride, $\mathrm{FeCl}_{3}$ and Group $\mathrm{E}$ was ferrous sulphate, $\mathrm{FeSO}_{4}$ impregnate with Ferric Chloride, $\mathrm{FeCl}_{3}$. In addition, sodium dodecyl sulphate (SDS), citric acid (CA), dimethicone 350 (D350) and epichlorohydrin, $\left(\mathrm{C}_{3} \mathrm{H}_{5} \mathrm{ClO}\right)$ used to strengthen the impregnation between magnetic particles and AC.

\section{Synthesis of Activated Carbon}

Raw coconut shell sample was collected from coconut milk manufacturer company, which is located at Tanah Merah district, Kelantan state. The raw coconut shell was carbonized by using modified drum method. Carbonization is a conversion of organic matters like biomass into carbon through destructive distillation. The activated carbon was produced through modified pyrolysis technique using an empty 55-gallon steel oil drum. The coconut shell was placed into the oil drum and lit from the bottom. Once the materials inside the drum were fully ignited and the water in the carbon source had evaporated, the drum was sealed to initiate the anoxic combustion process. The process would take about two to three hours for the material to be fully carbonized. Once the charcoal was completed, it was sorted by visual inspection to find material that had been thoroughly carbonized. Shells that retained a natural brown colour and that were difficult to break by hand were excluded. Any material that had not been completely carbonized was saved for the following batch. The drum method produced approximately $5 \mathrm{~kg}$ of carbon material. There is no fixed temperature in this process but can ranged from 400 to $500^{\circ} \mathrm{C}$ (Cobb et al., 2012). The schematic diagram on the preparation of activated carbon using carbonization drum method is illustrated in Figure 1. The carbonized coconut shells were grounded into the desired form and further subjected to activation with $1 \mathrm{~N}$ concentration of potassium hydroxide $(\mathrm{KOH})$ at a ratio of 1:3, with slow agitation at $75 \mathrm{rpm}$ for 1 hour. To prepare $1 \mathrm{~N} \mathrm{KOH}, 56.11 \mathrm{~g}$ of $\mathrm{KOH}$ was dissolved in $300 \mathrm{~mL}$ water and then transferred to a $1 \mathrm{~L}$ measuring flask quantitatively and dilute until it reaches 1 liter (Cobb et al., 2012). The mixture was left to mature for about 5 to 6 hour and followed by filtration, later, rinsed with double distilled water $\left(\mathrm{ddH}_{2} \mathrm{O}\right)$. The $\mathrm{AC}$ was dried in oven at temperature of $90-100^{\circ} \mathrm{C}$. The dried $\mathrm{AC}$ was placed in a muffle furnace (Carbolite ELF 11/6B) and heated to $800-900^{\circ} \mathrm{C}\left(10^{\circ} \mathrm{C} / \mathrm{min}\right)$, and kept for $15-30$ 


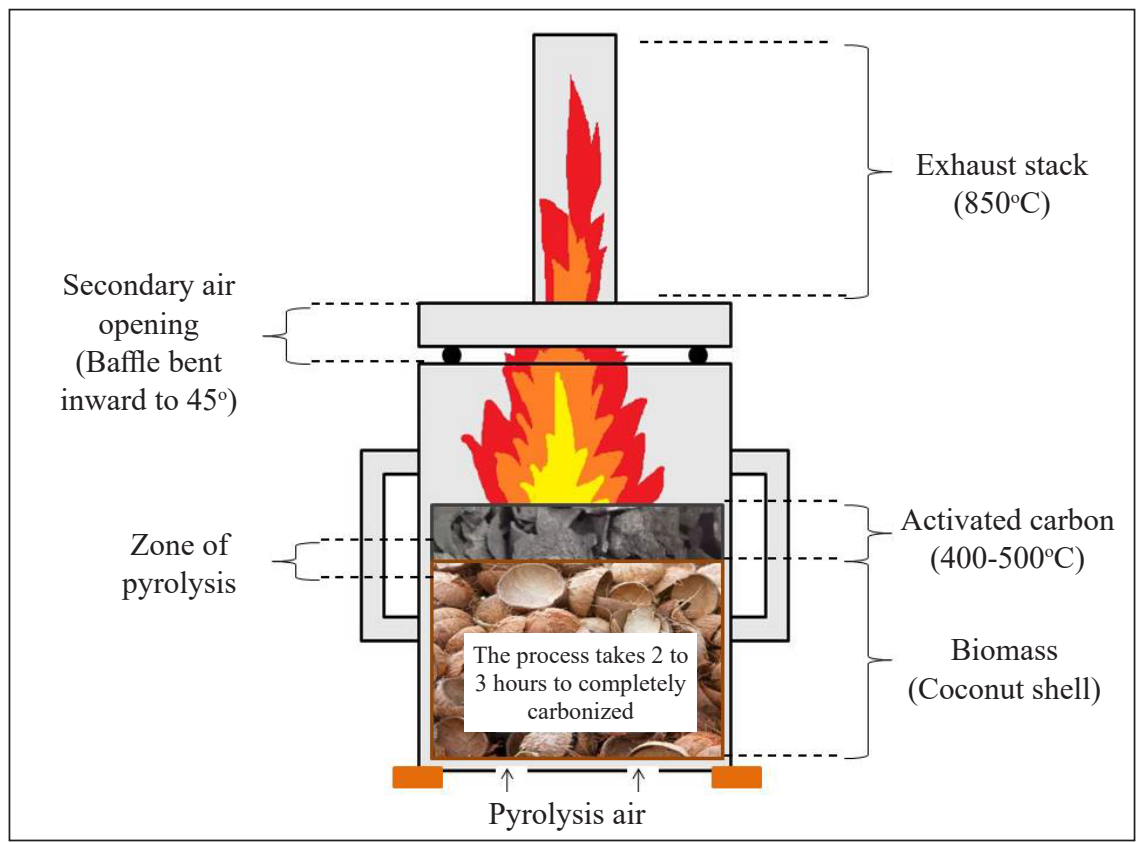

Figure 1. Schematic diagram on the synthesis of activated carbon from coconut shell via carbonization method

min (Lee et al., 2018). The cooled down sample was washed, neutralized with 5\% $\mathrm{HCl}$, dried and stored for further modification.

\section{Preparation Method for Magnetization of Coconut Shell Activated Carbon}

Table 1 displays the different combination of the final product by using different magnetic particles impregnated with different chemical and different sonicated treatment. The AC used was in mesh size of less than $45 \mu \mathrm{m}$. At first, $2.95 \mathrm{~g}$ of iron powder or iron (III) oxide powder, $\mathrm{Fe}_{2} \mathrm{O}_{3}$ (IFP, I30B, and I30) was dissolved in $45 \mathrm{~mL}$ of distilled water and placed in the orbital shaker for the agitation of $250 \mathrm{rpm}$ for $30 \mathrm{~min}$. For MAC, the experiment was continued with the addition of $6 \mathrm{~mL}$ of ammonium hydroxide solution, $\mathrm{NH}_{4} \mathrm{OH}(28 \%)$ and agitated for 1 hour. Next, $1.5 \mathrm{~g}$ of $\mathrm{AC}$ was added and continued the agitation for $5 \mathrm{~min}$. Then, the preparation was continued with addition of $0.6 \mathrm{ml}$ of different chemical (control, Dimetricone 350, Sodium Dodecyl Sulphate, and Citric Acid) respectively as enhancer of magnetization and continue agitated for another 1 hour. All of the samples were continued with 3 different sonication for 1 hour which is non-sonicated, ultrasonic bath and sonicated respectively. Lastly, the final product, MAC was washed and collected using neodymium magnet. The MAC was dried at $50^{\circ} \mathrm{C}$ in the oven to obtain the dry MAC powder. Group C (I30) contained the lowest magnetism among all the group which the magnetic particles used was the alpha phase of ferric oxide, $\alpha-\mathrm{Fe}_{2} \mathrm{O}_{3}$ which was the lowest magnetism among 
all magnetic particles. D350 was the worst chemical used to treat the sample which wasted lots of carbon sample during the washing process.

Table 1

Sample with different treatment combination using method 1

\begin{tabular}{ccccc}
\hline & & Non- sonicated (I) & Ultrasonic bath (II) & Sonicated (III) \\
\hline \multirow{3}{*}{ IFP (A) } & Control (1) & MAC_A1I & MAC_A1II & MAC_A1III \\
& D350 (2) & MAC_A2I & MAC_A2II & MAC_A2III \\
& SDS (3) & MAC_A3I & MAC_A3II & MAC_A3III \\
& CA (4) & MAC_A4I & MAC_A4II & MAC_A4III \\
\hline \multirow{3}{*}{ I30B (B) } & Control (1) & MAC_B1I & MAC_B1II & MAC_B1III \\
& D350 (2) & MAC_B2I & MAC_B2II & MAC_B2III \\
& SDS (3) & MAC_B3I & MAC_B3II & MAC_B3III \\
& CA (4) & MAC_B4I & MAC_B4II & MAC_B4III \\
\hline \multirow{2}{*}{ I30 (C) } & Control (1) & MAC_C1I & MAC_C1II & MAC_C1III \\
& D350 (2) & MAC_C2I & MAC_C2II & MAC_C2III \\
& SDS (3) & MAC_C3I & MAC_C3II & MAC_C3III \\
& CA (4) & MAC_C4I & MAC_C4II & MAC_C4III \\
\hline
\end{tabular}

Notes: $\mathrm{A}=\mathrm{IFP}$ (Iron Powder); $\mathrm{B}=\mathrm{I} 30 \mathrm{~B}\left(\gamma-\mathrm{Fe}_{2} \mathrm{O}_{3}\right) ; \mathrm{C}=\mathrm{I} 30\left(\alpha-\mathrm{Fe}_{2} \mathrm{O}_{3}\right) ; 1=$ Control; $2=\mathrm{D} 350 ; 3=\mathrm{SDS} ; 4$ $=\mathrm{CA} ; \mathrm{I}=$ Non-sonicated; II = Ultrasonic bath; III = Sonicated

\section{Preparation Method for Magnetization of Coconut Shell Activated Carbon using Method 2}

For the impregnation magnetization $1.95 \mathrm{~g}$ of $\mathrm{FeCl}_{3}$ was mixed with $0.7 \mathrm{~g}$ of $\mathrm{FeCl}_{2}$ (D) and then dissolved in $45 \mathrm{~mL}$ of distilled water and placed in the orbital shaker for the agitation at $250 \mathrm{rpm}$ for $30 \mathrm{~min}$ (Table 2). The sample was further added with $6 \mathrm{~mL}$ of ammonium hydroxide solution, $\mathrm{NH}_{4} \mathrm{OH}(28 \%)$ and continued agitation for another 1 hour. Then, 1.5 $\mathrm{g}$ of $\mathrm{AC}$ was added into the solution and the agitation continued for another 5 mins. The prepared solution was added with different chemical (control, SDS, and CA) and continued the agitation for another 1 hour. The sample were treated using three different method for 1 hour which was non-sonicated, ultrasonic bath and sonicated respectively. Lastly, the

Table 2

Sample with different treatment combination using method 2

\begin{tabular}{llll}
\hline & & Non- sonicated (I) & Ultrasonic bath (II) \\
\hline $\mathrm{FeCl}_{3}+\mathrm{FeCl}_{3}$ (D) & Control (1) & MAC_D1I & MAC_D1II \\
& SDS (3) & MAC_D3I & MAC_D3II \\
& $\mathrm{CA}(4)$ & MAC_D4I & MAC_D4II \\
\hline $\mathrm{FeCl}_{3}+\mathrm{FeSO}_{4}(\mathrm{E})$ & Control (1) & MAC_E1I & MAC_E1II \\
& SDS (3) & MAC_E3I & MAC_E3II \\
& CA (4) & MAC_E4I & MAC_E4II \\
\hline
\end{tabular}

Notes: $\mathrm{D}=\mathrm{FeCl}_{2} ; \mathrm{E}=\mathrm{FeSO}_{4} ; 1=$ Control; $3=\mathrm{SDS} ; 4$ = CA; I = Non-sonicated; $\mathrm{II}=$ Ultrasonic bath 
final product, was washed and collected using neodymium magnet. The treated MAC was dried at $50{ }^{\circ} \mathrm{C}$ in the oven to obtain the dry MAC powder. The magnetization method was repeated $\mathrm{FeCl}_{3}+\mathrm{FeSO}_{4}$ (E) by replacing the preparation formula (i) with formula (ii) (1.95 $\mathrm{g}$ of $\mathrm{FeCl}_{3}$ impregnated with $1.0 \mathrm{~g}$ of $\mathrm{FeSO}_{4}$ ).

\section{Process Performance}

Yield (\%). The total yield of MAC (\%) estimated by using the following Equation 1,

$$
\text { Total Yield of MAC }(\%)=\frac{\text { weight of MAC_XX produced }}{\text { weight of activated carbon sample }} \times 100 \%
$$

Methylene Blue Test. Methylene blue test was carried out using method described by Jadhav and Mohanraj (2016). Methylene blue solution was prepared by diluting the stock solution with $1000 \mathrm{ppm}$ to $2 \mathrm{ppm}$. A fixed parameter was measured in this adsorption experiment where the time taken of the MAC to decolorize the methylene blue (contact time) and the time taken of the sample fully attached to the magnet (magnetic contact time) were recorded. At first, $0.15 \mathrm{~g}$ of each sample were weighed and poured into 25 $\mathrm{mL}$ of methylene blue solution. The time taken to decolorize the methylene blue and the time of the sample fully attached to the magnet were recorded. The methylene blue test was conducted in triplicates under identical condition and average value was calculated. Next, the filtrate was analyzed using UV visible spectrophotometer (Thermo Scientific Genesys 20) at $668 \mathrm{~nm}$ (Islam et al., 2017). This was to further prove the effectiveness of the MAC in adsorption of methylene blue solution. The absorbance value was recorded in triplicate and the average value were also recorded. The percentage of dye removal by using different sample was calculated using mathematical Equation 2.

$$
\text { Percentage of dye removal }(\%)=\frac{(B-S)}{S} \times 100
$$

Where B (mg/ L) and S (mg/ L) are MB concentration at initial and after added MAC. The steps were repeated by using different concentration of methylene blue dye which was 5 ppm and $10 \mathrm{ppm}$.

Iodine Test. Iodine number was used to determine the adsorption of iodine on the activated carbon (Mianowski et al., 2007). The main principle was to determine the residual iodine concentration by titration with sodium thiosulfate standard solution after the quantitative sample and iodine standard solution were fully shaken under specific conditions to determine the iodine adsorption amount. Iodine adsorption value can be used as a qualitative indicator of microporous structure of activated carbon (Yang et al., 2020). 
Preparation of Iodine Solution ( $(0.1 \mathrm{~N})$. For the preparation of iodine solution $(0.1 \mathrm{~N}), 12.7$ $\mathrm{g}$ of iodine pearls and $19.1 \mathrm{~g}$ of potassium iodide (KI) were weighed. Next, around 2-5 mL of distilled water was added slowly and stirred using magnetic stirrer. Distilled water was added until $50 \mathrm{~mL}$ to completely dissolve the iodine pearl. The solution was allowed to stir for a minimum of 4 hours to make sure that all the crystals were completely dissolved. The solution was quantitatively transferred to a 1 L volumetric flask (ASTMD4607_14, 2014). The iodine solution $0.1 \mathrm{~N}$ must be stored in amber bottle due to its sensitivity to light.

Preparation of Sodium Thiosulphate, $\mathrm{Na}_{2} \mathrm{~S}_{2} \mathbf{O}_{3}(\mathbf{0 . 0 5} \mathrm{N})$. Around $12.4 \mathrm{~g}$ of sodium thiosulphate, $\mathrm{Na}_{2} \mathrm{~S}_{2} \mathrm{O}_{3}(0.05 \mathrm{~N})$ was dissolved in approximately $100 \mathrm{~mL}$ of freshly boiled distilled water and $0.1 \mathrm{~g}$ of sodium bicarbonate, $\mathrm{NaHCO}_{3}$ was added to decrease the bacterial decomposition of the thiosulphate solution. The mixture was transferred quantitatively to a $1 \mathrm{~L}$ volumetric flask and diluted to the mark (ASTMD460714, 2014).

Preparation of Starch Solution. To prepare a starch solution, $1.0 \pm 0.5 \mathrm{~g}$ of starch was mixed with 5 to $10 \mathrm{~mL}$ of cold water to make a paste. Additional of $25 \pm 5 \mathrm{~mL}$ of water was added while stirring to the starch paste. The mixture was poured into a $1 \mathrm{~L}$ boiling water and boiled for 4 to 5 min (ASTMD460714, 2014).

Iodine Number. Iodine number was determined on iodine solution as blank, $45 \mu \mathrm{m}$ of $\mathrm{AC}, 63 \mu \mathrm{m}$ of AC, CMAC, the best and worst condition of sample, MAC_XX. The test divided into two parts as part $\mathrm{a}$ and $\mathrm{b}$. Part $\mathrm{b}$ was a blank reading. At first, $10 \mathrm{~mL}$ of iodine solution $(0.1 \mathrm{~N})$ was measured and poured into conical flask. The solution was titrated with sodium thiosulphate solution, $(0.05 \mathrm{~N})$ until the solution turn to pale yellow. Then, 2 drops of starch solution were added, and the solution turned blue. The solution was continued with titration of sodium thiosulphate until the solution turned colorless. The burette reading corresponds to blank reading (b). For part a, around $0.2 \mathrm{~g}$ of sample (AC, MAC, MAC_XX) was weighed and dissolved in $40 \mathrm{~mL}$ of iodine solution $0.1 \mathrm{~N}$. The solution was shaken for $50 \mathrm{~min}$ at $200 \mathrm{rpm}$ in the orbital shaker and filtered. Then, $10 \mathrm{~mL}$ of filtrate was measured and poured into another conical flask. The filtrate was titrated with sodium thiosulphate solution until the solution turns pale yellow. Next, 2 drops of starch solution were added into the solution until the solution turns blue. The solution was continued with the titration of sodium thiosulphate until the solution turned colorless. The burette readings were correspond to (a). The iodine value was calculated by using Equations 3 to 5 as stated below.

Iodine value $=\mathrm{c} \times$ Conversion factor; $\mathrm{mg} / \mathrm{g}$ 
Conversion factor $=$

molecular weight of iodine $\times$ normality of iodine $\times 40$

weight of activated carbon

$$
\begin{aligned}
& =\frac{127 \times 0.1 \mathrm{~N} \times 40}{0.2 \mathrm{~g}} \times \mathrm{b} \\
& \mathrm{c}=\mathrm{b}-\mathrm{a}
\end{aligned}
$$

\section{Characterization of magnetic activated carbon}

Scanning Electron Microscopy (SEM) Analysis. SEM was used to analyze the pore structure of AC and MAC sample that produced. The magnification used were $1000 \times$. The sample was placed on the SEM holder and moulded into the mounting holed in a JEOL JSM-IT100 scanning electron microscope. The focus knob was adjusted and the selected image captured.

X-ray Diffraction (XRD). X-ray diffraction is method a that uses X-ray to characterize the crystalline properties of carbon material. The sample was packed into the sample holder and analyzed by using Bruker D2 Phaser. The sample was scanned from $20.0^{\circ} \mathrm{C}$ to $90.0^{\circ} \mathrm{C}$ at the scan speed of $2^{\circ} \mathrm{min}^{-1}$. The XRD diffractogram patterns was obtained from the system.

\section{RESULTS AND DISCUSSION}

\section{Weight and Yield of Magnetic Activated Carbon}

Table 3 shows the weight and the total yield of the MAC. Magnetic activated carbon was produced by using different type of iron powder (A, B, C, D, and E), different chemical to treat $\operatorname{MAC}(1,2,3$, and 4) and also different type of sonication (I, II, and III). The production yield was considered as an important parameter in the feasibility study under specified condition. The magnetism of these MAC sample was tested using neodymium magnet $(\mathrm{NdFeB})$. The results showed that the magnetism of group $\mathrm{C}$ was the lowest. The results clearly showed that the MAC yield of all samples was more than $100 \%$. This is because the addition of different type of iron powder into different samples. The highest MAC yield, $417.33 \%$ was achieved by MAC_A4II (True yield: $140.67 \%$ ). The lowest MAC yield among all sample was from MAC_E3II that recorded 86\% (True yield: 28.99\%). This happened because of the washing and cleaning process that washed away most of the AC. Besides, this could also be due to the failure of impregnation process to impregnate the $\mathrm{FeSO}_{4}$ powder and the $\mathrm{AC}$. 
Table 3

Weight and percentage of MAC yield (\%)

\begin{tabular}{|c|c|c|c|c|}
\hline No & Sample & Weight (g) & Total Yield of MAC (\%) & True Yield (\%) \\
\hline 1 & MAC_A1I & 3.29 & 219.33 & 73.93 \\
\hline 2 & MAC_A1II & 4.74 & 316.00 & 106.52 \\
\hline 3 & MAC_A2I & 3.34 & 222.67 & 75.06 \\
\hline 4 & MAC_A2II & 3.85 & 256.67 & 86.52 \\
\hline 5 & MAC_A2III & 3.28 & 218.67 & 73.71 \\
\hline 6 & MAC_A3I & 4.80 & 320.00 & 107.87 \\
\hline 7 & MAC_A3II & 4.94 & 329.33 & 111.01 \\
\hline 8 & MAC_A3III & 4.66 & 310.67 & 104.72 \\
\hline 9 & MAC_A4I & 4.61 & 307.33 & 103.60 \\
\hline 10 & MAC_A4II & 6.26 & 417.33 & 140.67 \\
\hline 11 & MAC_A4III & 4.16 & 277.33 & 93.48 \\
\hline 1 & MAC_B1I & 4.14 & 276.00 & 93.03 \\
\hline 2 & MAC_B1II & 4.31 & 287.33 & 96.85 \\
\hline 3 & MAC_B2I & 3.71 & 247.33 & 83.37 \\
\hline 4 & MAC_B2II & 3.53 & 235.33 & 79.33 \\
\hline 5 & MAC_B2III & 3.82 & 254.67 & 85.84 \\
\hline 6 & MAC_B3I & 3.50 & 233.33 & 78.65 \\
\hline 7 & MAC_B3II & 3.61 & 240.67 & 81.12 \\
\hline 8 & MAC_B3III & 3.93 & 262.00 & 88.31 \\
\hline 9 & MAC_B4I & 3.12 & 208.00 & 70.11 \\
\hline 10 & MAC_B4II & 4.71 & 314.00 & 105.84 \\
\hline 11 & MAC_B4III & 3.61 & 240.67 & 81.12 \\
\hline 12 & MAC_C1I & 4.08 & 272.00 & 91.69 \\
\hline 13 & MAC_C1II & 4.17 & 278.00 & 93.71 \\
\hline 14 & MAC_C2I & 3.87 & 258.00 & 86.97 \\
\hline 15 & MAC_C2II & 4.21 & 280.67 & 94.61 \\
\hline 16 & MAC_C2III & 4.32 & 288.00 & 97.08 \\
\hline 17 & MAC_C3I & 4.36 & 290.67 & 97.98 \\
\hline 18 & MAC_C3II & 4.23 & 282.00 & 95.06 \\
\hline 19 & MAC_C3III & 4.11 & 274.00 & 92.36 \\
\hline 20 & MAC_C4I & 4.09 & 272.67 & 91.91 \\
\hline 21 & MAC_C4II & 4.21 & 280.67 & 94.61 \\
\hline 22 & MAC_C4III & 4.71 & 314.00 & 105.84 \\
\hline 23 & MAC_D1I & 2.55 & 170.00 & 57.30 \\
\hline 24 & MAC_D1II & 2.17 & 144.67 & 48.76 \\
\hline 25 & MAC_D3I & 2.16 & 144.00 & 48.54 \\
\hline 26 & MAC_D3II & 2.60 & 173.33 & 58.43 \\
\hline 27 & MAC_D4I & 2.13 & 142.00 & 47.87 \\
\hline 28 & MAC_D4II & 2.15 & 143.33 & 48.31 \\
\hline 29 & MAC_E1I & 2.08 & 138.67 & 46.74 \\
\hline 30 & MAC_E1II & 2.03 & 135.33 & 45.62 \\
\hline 31 & MAC_E3I & 2.07 & 138.00 & 46.52 \\
\hline 32 & MAC_E3II & 1.29 & 86.00 & 28.99 \\
\hline 33 & MAC_E4I & 2.12 & 141.33 & 47.64 \\
\hline 34 & MAC_E4II & 2.38 & 158.67 & 53.48 \\
\hline
\end{tabular}

Notes: $\mathrm{A}=\mathrm{IFP}$ (Iron Powder); $\mathrm{B}=\mathrm{I} 30 \mathrm{~B}\left(\gamma-\mathrm{Fe}_{2} \mathrm{O}_{3}\right) ; \mathrm{C}=\alpha-\mathrm{Fe}_{2} \mathrm{O}_{3} ; \mathrm{D}=\mathrm{FeCl}_{2} ; \mathrm{E}=\mathrm{FeSO}_{4} ; 1=\mathrm{Control} ; 2=$ D350; 3 = SDS; 4 = CA; I = Non-sonicated; II = Ultrasonic bath; III = Sonicated. 


\section{Methylene Blue Test}

The behavior of methylene blue and iodine test were closely related to surface area and pores volume of the carbon sample. The parameter used in methylene blue test were the time taken by MAC to decolorize methylene blue solution (contact time) and the time taken by MAC fully attached to magnet (magnetic contact time). For methylene blue test, the selected MAC samples were from group A, B, D and E. Group C was not selected because group $\mathrm{C}$ did not contain any magnetism which was considered as lowest quality if compared with others. Table 4 shows the contact time and the magnetic contact time between the MAC sample and 2 ppm methylene blue. Additionally, the absorbance value had been recorded that measured at $668 \mathrm{~nm}$ by using UV-VIS. Besides, the test had been done triplicates and the average result was calculated. The results showed the contact time, magnetic contact time of the MAC form by using the iron powder (IFP) and treated with different chemical (control, D350, SDS and citric acid) and sonicated way (non-sonicated, ultrasonic bath and sonicated). The sample that achieved the shortest contact time was MAC_A3I which recorded $5.38 \mathrm{~s}$ and on the other hand the longest contact time recorded was by MAC_A2III which was 156.73 s. This explained that MAC_A3I applied shorter time to decolorize the methylene blue whereas MAC_A2III applied the longest time. For the magnetic contact time, the shortest time, 17.43 s recorded byMAC_A2III and the longest time, $40.87 \mathrm{~s}$ recorded by MAC_A2I. The result clarifies that some MAC have good methylene blue adsorption but weak magnetism. The magnetism of the MAC sample was affected by different types of iron powder used and the treated chemical.

Group B was the MAC prepared by using gamma phase of ferric oxide, $\gamma-\mathrm{Fe}_{2} \mathrm{O}_{3}$ (I30B) and treated by different chemical (control, D350, SDS and citric acid) and sonicated way (non-sonicated, ultrasonic bath and sonicated). Based on Table 4, MAC_B3I had recorded the shortest contact time which was $3.90 \mathrm{~s}$ whereas on the other hand MAC_B2I had recorded the longest contact time, $50.54 \mathrm{~s}$. Furthermore, for the longest and shortest magnetic contact time, MAC_B2III and MAC_B1I recorded were $6.283 \mathrm{~s}$ and $71.87 \mathrm{~s}$ respectively.

The MAC from group D was carried out by corporate ferrous chloride $\left(\mathrm{FeCl}_{2}\right)$ with ferric chloride $\left(\mathrm{FeCl}_{3}\right)$. For group D, MAC_D3I and MAC_D1I had recorded the shortest and longest contact time when dissolved in methylene blue solution. Moreover, for the magnetic contact time, MAC_D3I displayed the best magnetism and conversely MAC_D1I displayed the worst magnetism among category D. The time recorded were $28.64 \mathrm{~s}$ and 35.91 s respectively. MAC_E which the group E was MAC that were manufactured by mixing the ferric chloride $\left(\mathrm{FeCl}_{2}\right)$ with ferrous sulphate $\left(\mathrm{FeSO}_{4}\right)$. Lastly for treatment Group E, the results showed that MAC_E3I and MAC_E4II had presented the shortest and longest contact time when they dissolved in methylene blue solution. The time recorded were $3.73 \mathrm{~s}$ and 4.54 respectively which also explained that MAC_E3I was more effective 
Table 4

Methylene blue (2 ppm) test using different treatments

\begin{tabular}{|c|c|c|c|c|c|}
\hline No & Sample & $\begin{array}{l}\text { Contact } \\
\text { Time (s) }\end{array}$ & $\begin{array}{c}\text { Magnetic Contact } \\
\text { Time (s) } \\
\end{array}$ & $\begin{array}{l}\text { Absorbance Value } \\
\text { (at wavelength of } 668 \mathrm{~nm} \text { ) }\end{array}$ & $\begin{array}{l}\text { Percentage of } \\
\text { dye removal }(\%)\end{array}$ \\
\hline 1 & MAC_A1I & 6.857 & 38.537 & $0.064 \pm 0.004$ & 81.009 \\
\hline 2 & MAC_A1II & 10.713 & 30.743 & $0.060 \pm 0.006$ & 82.196 \\
\hline 3 & MAC_A2I & 15.717 & 40.870 & $0.010 \pm 0$ & 97.033 \\
\hline 4 & MAC_A2II & 32.283 & 31.380 & $0.102 \pm 0.002$ & 69.733 \\
\hline 5 & MAC_A2III & 156.733 & 17.430 & $0.194 \pm 0.0005$ & 42.433 \\
\hline 6 & MAC_A3I & 5.357 & 35.140 & $0.013 \pm 0.0011$ & 96.142 \\
\hline 7 & MAC_A3II & 7.427 & 33.420 & $0.004 \pm 0.0005$ & 98.81 \\
\hline 8 & MAC_A3III & 10.437 & 30.310 & $0.003 \pm 0.0005$ & 99.110 \\
\hline 9 & MAC_A4I & 21.107 & 19.790 & $0.009 \pm 0.0005$ & 97.329 \\
\hline 10 & MAC_A4II & 11.883 & 35.110 & $0.015 \pm 0.001$ & 95.549 \\
\hline 11 & MAC_A4III & 19.643 & 19.530 & $0.011 \pm 0.001$ & 96.736 \\
\hline 1 & MAC_B1I & 5.533 & 71.867 & $0.017 \pm 0.0005$ & 94.955 \\
\hline 2 & MAC_B1II & 4.620 & 55.490 & $0.014 \pm 0.0005$ & 95.846 \\
\hline 3 & MAC_B2I & 50.540 & 10.723 & $0.080 \pm 0.0005$ & 76.261 \\
\hline 4 & MAC_B2II & 37.327 & 13.197 & $0.036 \pm 0$ & 89.318 \\
\hline 5 & MAC_B2III & 44.497 & 6.283 & $0.118 \pm 0.0015$ & 64.985 \\
\hline 6 & MAC_B3I & 3.903 & 54.997 & $0.005 \pm 0.001$ & 98.516 \\
\hline 7 & MAC_B3II & 4.040 & 53.527 & $0.009 \pm 0.0005$ & 97.329 \\
\hline 8 & MAC_B3III & 3.953 & 45.783 & $0.003 \pm 0.0005$ & 98.110 \\
\hline 9 & MAC_B4I & 5.737 & 49.437 & $0.030 \pm 0$ & 91.098 \\
\hline 10 & MAC_B4II & 3.953 & 42.993 & $0.019 \pm 0.0005$ & 94.362 \\
\hline 11 & MAC_B4III & 5.870 & 50.910 & $0.007 \pm 0$ & 97.923 \\
\hline 1 & MAC_D1I & 4.727 & 30.070 & $0.049 \pm 0.0005$ & 85.460 \\
\hline 2 & MAC_D1II & 3.917 & 35.910 & $0.082 \pm 0.001$ & 75.668 \\
\hline 3 & MAC_D3I & 3.600 & 28.640 & $0.067 \pm 0$ & 80.119 \\
\hline 4 & MAC_D3II & 4.423 & 34.120 & $0.098 \pm 0.0005$ & 70.920 \\
\hline 5 & MAC_D4I & 3.803 & 35.270 & $0.055 \pm 0.0005$ & 83.680 \\
\hline 6 & MAC_D4II & 4.183 & 34.510 & $0.059 \pm 0.0005$ & 82.493 \\
\hline 1 & MAC_E1I & 4.000 & 48.640 & $0.089 \pm 0.0017$ & 73.591 \\
\hline 2 & MAC_E1II & 4.533 & 46.680 & $0.074 \pm 0.001$ & 78.042 \\
\hline 3 & MAC_E3I & 3.733 & 47.450 & $0.060 \pm 0.0005$ & 82.196 \\
\hline 4 & MAC_E3II & 4.343 & 41.170 & $0.085 \pm 0.0005$ & 74.777 \\
\hline 5 & MAC_E4I & 4.183 & 54.290 & $0.103 \pm 0.00153$ & 69.436 \\
\hline 6 & MAC_E4II & 4.540 & 52.220 & $0.055 \pm 0.0005$ & 83.680 \\
\hline
\end{tabular}

Where $\mathrm{n}=3$ for triplicate test of methylene blue test. Notes: $\mathrm{A}=\mathrm{IFP}$ (Iron Powder); $\mathrm{B}=\mathrm{I} 30 \mathrm{~B}\left(\gamma-\mathrm{Fe}_{2} \mathrm{O}_{3}\right) ; \mathrm{D}=$ $\mathrm{FeCl}_{2} ; \mathrm{E}=\mathrm{FeSO}_{4} ; 1=$ Control; 2 = D350; 3 = SDS; 4 = CA; I = Non-sonicated; II = Ultrasonic bath; III = Sonicated 
if compared with MAC_E4II. Additionally, MAC_E3II and MAC_E4I had recorded 41.17 $\mathrm{s}$ and $54.29 \mathrm{~s}$ as the shortest and longest magnetic contact time. Table 5 showed the contact and magnetic contact time of the CMAC and AC. The result showed that the CMAC recorded the contact time of the sample in methylene blue solution as $4.13 \mathrm{~s}$ and 50.81 $\mathrm{s}$ as the magnetic contact time. On the other hand, due to AC not containing magnetism, the AC only recorded $9.58 \mathrm{~s}$ for the contact time of sample in methylene blue solution.

Table 5

Methylene blue (2 ppm) test

\begin{tabular}{cccccc}
\hline \multirow{2}{*}{ No } & Sample & $\begin{array}{c}\text { Contact } \\
\text { Time (s) }\end{array}$ & $\begin{array}{c}\text { Magnetic Contact } \\
\text { Time (s) }\end{array}$ & \multicolumn{2}{c}{$\begin{array}{c}\text { Absorbance Value } \\
(\mathbf{6 6 8} \mathbf{~ n m})\end{array}$} \\
\cline { 3 - 6 } & Average & Average & Average & Percentage of dye removal (\%) \\
\hline 1 & CMAC & 4.127 & 50.810 & 0.098 & 70.920 \\
2 & AC & 9.580 & - & 0.244 & 27.596 \\
\hline
\end{tabular}

\section{Iodine Test}

Iodine test for selected MAC sample were calculated by using Equation 3 to 5 . The iodine number of the selected sample is shown in Table 6. The sample was selected based on the highest and the lowest of the percentage of dye removal from methylene blue test.

Table 6

Iodine number for selected MAC sample

\begin{tabular}{ccc}
\hline No & Sample & Iodine Value $(\mathrm{mg} / \mathrm{g})$ \\
\hline 1 & $45 \mu \mathrm{m}$ AC & 925.840 \\
2 & $63 \mu \mathrm{m}$ AC & 874.948 \\
3 & CMAC & 657.301 \\
4 & MAC_A2III & 821.627 \\
5 & MAC_A3II & 652.606 \\
6 & MAC_B2III & 368.710 \\
7 & MAC_B3I & 275.069 \\
8 & MAC_D1I & 719.862 \\
9 & MAC_D3II & 737.419 \\
10 & MAC_E4I & 795.945 \\
11 & MAC_E4II & 782.240 \\
\hline
\end{tabular}

Notes: $\mathrm{A}=\mathrm{IFP}$ (Iron Powder); $\mathrm{B}=\mathrm{I} 30 \mathrm{~B}\left(\gamma-\mathrm{Fe}_{2} \mathrm{O}_{3}\right) ; \mathrm{D}=\mathrm{FeCl}_{2} ; \mathrm{E}=\mathrm{FeSO}_{4} ; 1=$ Control; 2 = D350; 3 = SDS; I $=$ Non-sonicated; II = Ultrasonic bath; III = Sonicated

Iodine test was used to determine the surface area of the MAC and AC. Additionally, iodine test also act as a measure of micropore content of $\mathrm{AC}$ by observing the iodine adsorption from the solution. As shown in Tables 3 and 4, there are comparison between 
$\mathrm{AC}$ and MAC. At first, the comparison between $45 \mu \mathrm{m} \mathrm{AC}$ and $63 \mu \mathrm{m}$ AC was made. The result clearly showed that the iodine number of $45 \mu \mathrm{m}$ AC was higher than $63 \mu \mathrm{m} \mathrm{AC.} 45$ $\mu \mathrm{m}$ AC recorded $925.84 \mathrm{mg} / \mathrm{g}$ whereas $63 \mu \mathrm{m}$ AC recorded $874.95 \mathrm{mg} / \mathrm{g}$ of iodine number. The higher iodine number indicates a higher degree of activation (Machrouhi et al., 2019). Besides, higher iodine number indicates that the $45 \mu \mathrm{m} \mathrm{AC}$ contain a larger porosity and higher number of porosity (Arslanoglu, 2019). The result showed that $45 \mu \mathrm{m} \mathrm{AC}$ had higher quality compared to $63 \mu \mathrm{m} \mathrm{AC}$. The iodine test for MAC was also calculated for comparison. For group A, MAC_A3II recorded a lower iodine adsorption number, 652.606 $\mathrm{mg} / \mathrm{g}$ which indicated it was better compared to MAC_A2III that recorded higher iodine adsorption number, $821.63 \mathrm{mg} / \mathrm{g}$ (Figure 2). Next, for the comparison of other group B, $\mathrm{D}$ and E, the more qualified MAC are MAC_B3I, MAC_D1I and MAC_E4II. The iodine adsorption number recorded are $275.07 \mathrm{mg} / \mathrm{g}, 719.86 \mathrm{mg} / \mathrm{g}$ and $782.24 \mathrm{mg} / \mathrm{g}$ respectively. MAC_B3I recorded the lowest iodine adsorption number which indicated that the surface of MAC_B3I are mostly covered by iron ion (Deng et al., 2010). The iodine adsorption number of MAC are much lower compared to AC because of the surface of MAC were mostly covered by iron ion depending on the type of magnetic agent used. Besides, this further explained that MAC_A3II having a lower iodine adsorption number had a smaller number of micropores and the surface of carbon were mostly covered by iron ion.

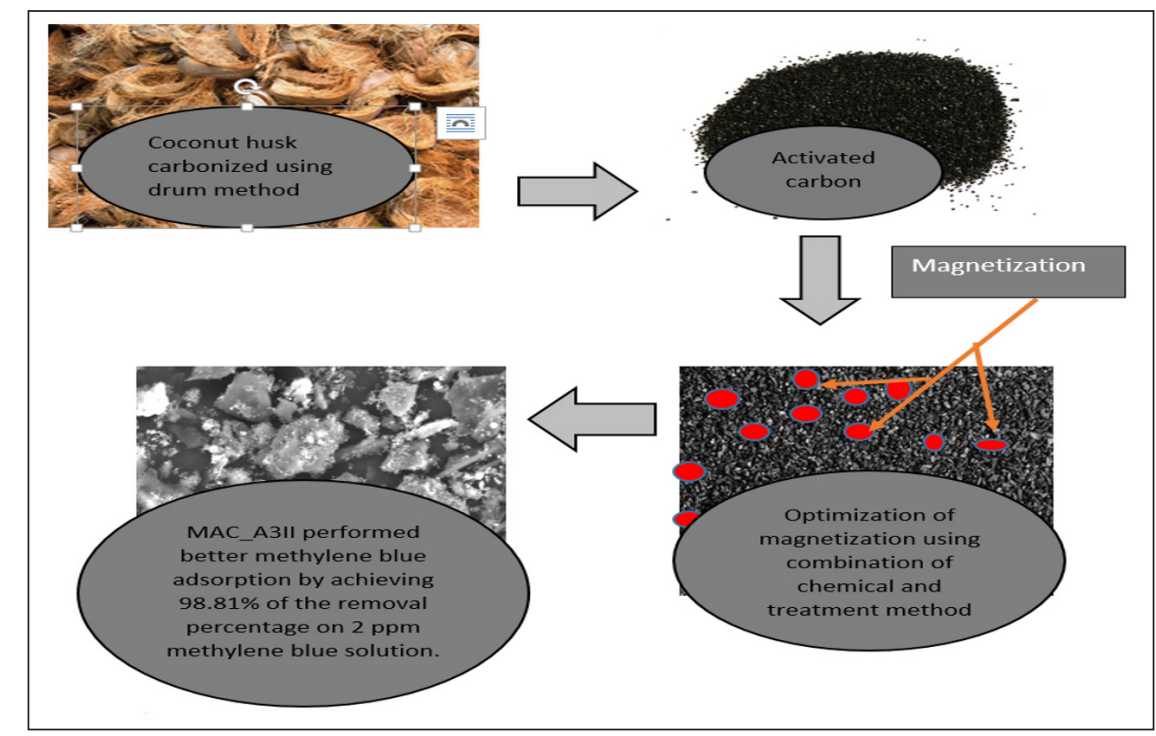

Figure 2. Process flow on the synthesis of magnetic activated carbon treated with sodium dodecyl sulphate

\section{Characterization of Magnetic Activated Carbon}

Scanning Electron microscope. Scanning electron microscopy analysis is an analytical technique to study the physical properties of the carbon. This analysis was mainly to illustrate the pore structure or the morphology of the carbon sample. Figure 3 depicts the 


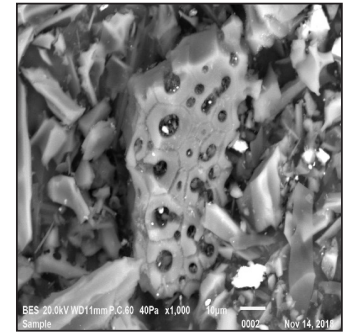

(a)

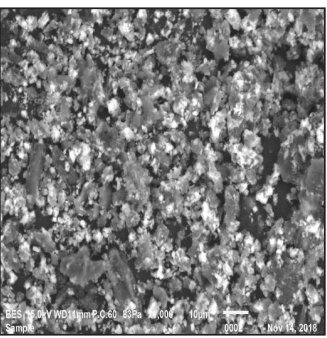

(b)

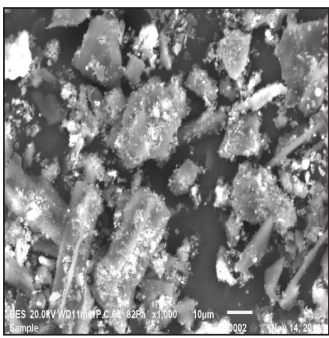

(c)

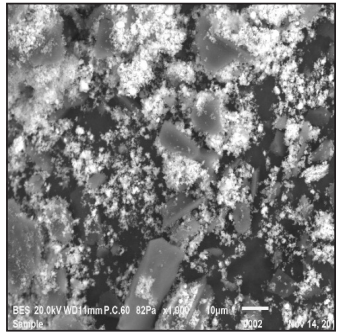

(d)

Figure 3. Micrograph of carbon material at magnification of 1000×: (a) AC; (b) CMAC; (c)MAC_A3II; and (d) MAC_B2III

micrograph and image of the chosen sample under the magnification of 1000x. The sample were chosen based on the best condition on iodine test and methylene blue test and samples chosen were the AC, CMAC, MAC_A3II and MAC_B2III. Figure 3 shows the micrograph related to AC. As seen on the micrograph, there were abundant pores developed on the AC $(1000 x)$. The pores were randomly scattered on the surface of the activated carbon with various size, diameter, and width of external pores. Besides, there was also some white particles spotted on the surface of the carbon. This might be due to the impurities that was not washed completely during the washing process (Anyika, et al., 2017). The micrograph of the AC showed many micropores and mesopores compared to other samples. This was certainly proof with the iodine number that are higher if compared to other samples. The micrographs of CMAC, MAC_A3II and MAC_B2III are depicted in Figure 3 b, c, and $\mathrm{d}$, respectively. The micrograph of all MAC sample does not show obvious pores if compared to activated carbon. This is because the iron powder used have blocked the pores of the MAC (Suresh et al., 2017). Furthermore, the carbon surface of CMAC showed a homogeneous surface whereas micrograph of MAC_A3II and MAC_B2III showed that the particle size was not homogeneous.

The micrograph of MAC_A3II displayed bigger and uneven size of particle compared to CMAC. In addition, MAC_A3II also showed some needle like structure which represented the presence of ferrous oxide. Moreover, MAC_B2III contained less greyish layer compared to the others. The greyish layer might represent some of the chemical that added to strengthen the magnetism of the MAC. Next, there were some white spots scattered around the surface of each magnetized sample. The white spot was believed to act as the silica particles and MAC_B2III contained more white spots because of the addition of D350 chemical that were contained in silica particles (Wang, et al., 2017).

X-Ray Diffraction (XRD). X-ray diffraction is the analytical technique that mainly identify the crystalline phase of the sample tested. The selected samples were analyzed by using $\mathrm{X}$-ray diffraction analysis as shown on Figure 4. Diffractogram of AC showed some intense 


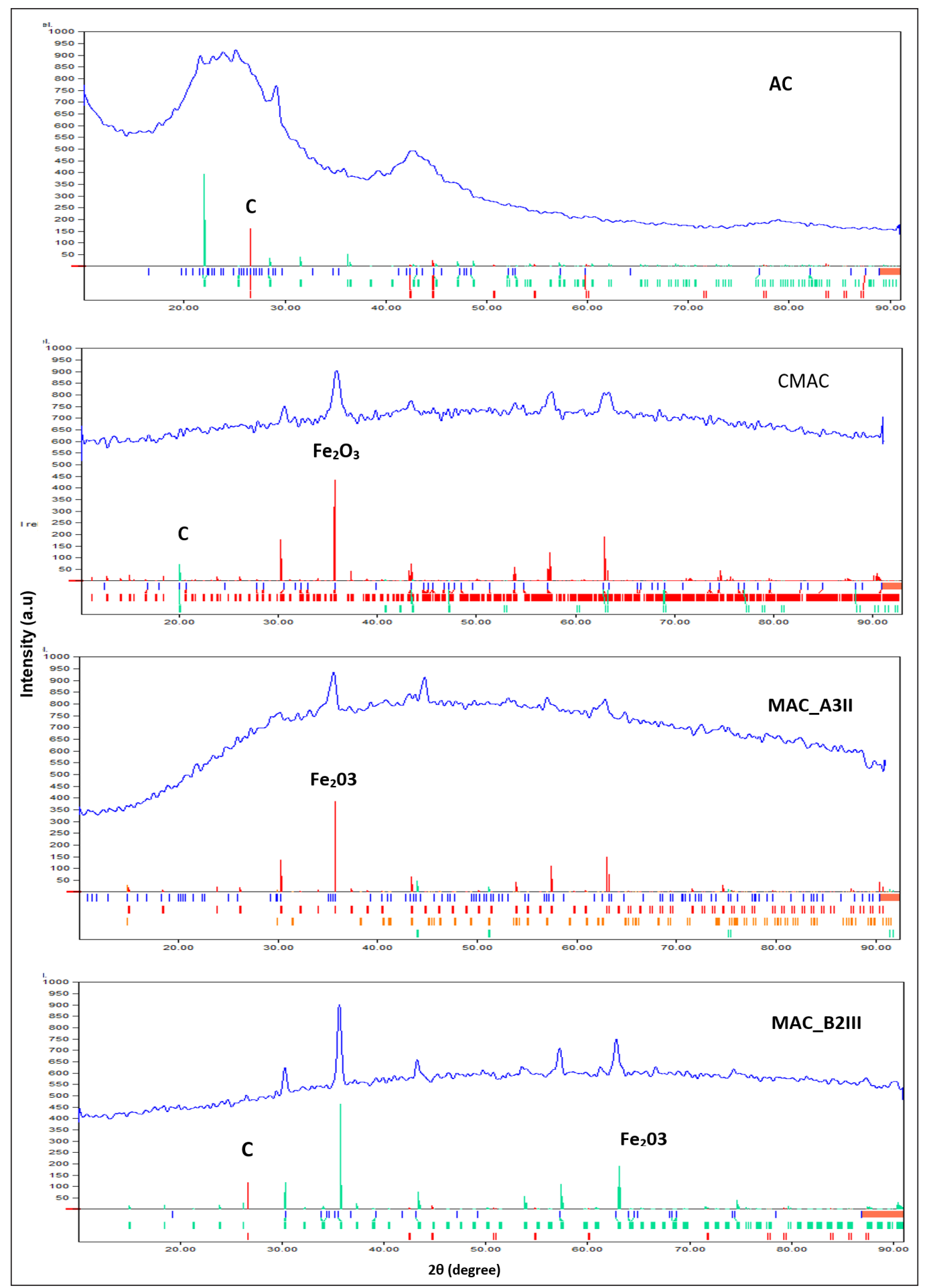

Figure 4. XRD diffractogram of AC, CMAC, MAC_A3II and MAC_B2III

(Note: $\mathrm{A}=\mathrm{IFP}$ (iron powder); $\mathrm{B}=\mathrm{I} 30 \mathrm{~B}\left(\gamma-\mathrm{Fe}_{2} \mathrm{O}_{3}\right) ; 2=\mathrm{D} 350 ; 3=\mathrm{SDS} ; \mathrm{II}=$ ultrasonic bath; III = Sonicate) 
peaks which assigned to the presence of carbon at $2 \theta 26.54^{\circ}, 42.42^{\circ}, 59.74^{\circ}$, and $87.55^{\circ}$ at intensity of 596.95, 483.38, 181.95 and 181.85, respectively. Diffractogram of AC shows that AC contained $47.8 \%$ of graphite compound. Diffractogram of CMAC had shown the main composition was iron oxide at $90.3 \%$. The most important structure in MAC was the iron compound that leads to the magnetism of the AC. The diffractogram had shown a few peaks which matched to ferric oxide at $2 \theta 30.54^{\circ}, 35.71^{\circ}$ and $62.80^{\circ}$ at the intensity of 418.86, 1000.00, and 456.86, respectively. The presence of iron oxides indicates that the CMAC contains magnetism. Furthermore, diffractogram of MAC_A3II displayed the many peaks that related to ferrous oxide. There were some intense peaks that matched to ferric oxide at $2 \theta 30.26^{\circ}$ and $35.68^{\circ}$ at the intensity of 394.73 and 853.49 , respectively. Diffractogram of MAC_B2III shows some peaks at $2 \theta 35.55^{\circ}$ and $63.96^{\circ}$ that matched to maghemite and carbon whereas $2 \theta 26.54^{\circ}$ that matched to carbon.

\section{CONCLUSION}

This study revealed that MAC_A3II had presented a better characteristic compared with other adsorbent samples, CMAC and the AC. MAC_A3II produced by impregnated the iron powder with SDS as the treated chemical and sonicated by using ultrasonic bath. Moreover, MAC_A3II performed better methylene blue adsorption by achieving $98.81 \%$ of the removal percentage on 2 ppm methylene blue solution. The iodine test of MAC_A3II, $626.61 \mathrm{mg} / \mathrm{g}$ was lower than the AC which was $925.84 \mathrm{mg} / \mathrm{g}$. This showed that $\mathrm{AC}$ were highly porous and had larger surface area. On the other hand, MAC_A3II had lower iodine number because the iron had blocked the surface of the carbon. The SEM analysis clearly showed that AC contained many micropores and mesopores if compared with MAC. Besides, for SEM analysis of MAC, the micropores and mesopores were very hard to identified as the pores were blocked by the iron or silicone atom. From the analysis it can be concluded that MAC_A3II presented better qualities and characteristics on the methylene blue adsorption and magnetism if compared to AC and CMAC. MAC_A3II prepared by using the iron powder and treated by adding SDS, was proven as the best qualities of MAC. The presence of iron oxide had been verified by using XRD analysis.

\section{ACKNOWLEDGEMENT}

The authors acknowledge the support from Universiti Malaysia Kelantan (R/SGJP/ A07.00/01397A/005/2018/00570).

\section{REFERENCES}

Anyika, C., Asri, N. A. M., Majid, Z. A., Yahya, A., \& Jaafar, J. (2017). Synthesis and characterization of magnetic activated carbon developed from palm kernel shells. Nanotechnology for Environmental Engineering, 2(1), 1-16. doi: https://doi.org/10.1007/s41204-017-0027-6 
Arslanoglu, H. (2019). Direct and facile synthesis of highly porous low cost carbon from potassium-rich wine stone and their application for high-performance removal. Journal of Hazardous Materials, 374, 238-247. doi: https://doi.org/10.1016/j.jhazmat.2019.04.042

ASTM D4607-14. (2014). Standard test method for determination of iodine number of activated carbon. West Conshohocken, USA: ASTM International.

Cobb, A., Warms, M., Maurer, E. P., \& Chiesa, S. (2012). Low-tech coconut shell activated charcoal production. International Journal for Service Learning in Engineering, 7(1), 93-104.

Deng, H., Li, G., Yang, H., Tang, J., \& Tang, J. (2010). Preparation of activated carbons from cotton stalk by microwave assisted $\mathrm{KOH}$ and $\mathrm{K}_{2} \mathrm{CO}_{3}$ activation. Chemical Engineering Journal, 163(3), 373-381. doi: https://doi.org/10.1016/j.cej.2010.08.019

Ewadh, H. M. (2020). Removal of methylene blue by coontail (Ceratophyllum demersum) using phytoremediation concept. Plant Archives, 20(1), 2677-2681.

Hindryawati, N., Dirgarini, J. N. S. R. R., Panggabean, A. S., \& Wilsoma. (2020). Ultrasound assisted the degradation of methylene blue using WO3- deoiled spent bleaching earth as a catalyst. IOP Conference Series: Earth and Environmental Science, 854(1), 1-8.

Islam, M. A., Ahmed, M. J., Khanday, W. A., Asif, M., \& Hameed, B. H. (2017). Mesoporous activated coconut shell-derived hydrochar prepared via hydrothermal carbonization- $\mathrm{NaOH}$ activation for methylene blue adsorption. Journal of Environmental Management, 203, 237-244. doi: https://doi.org/10.1016/j. jenvman.2017.07.029

Jadhav, A., \& Mohanraj, G. (2016). Synthesis of activated carbon from Cocos nucifera leaves agrowaste by chemical activation method. Chemistry and Chemical Technology, 10(2), 201-208.

Jamaludin, M. Z. (2020). Study on removal of pollutant from batik wastewater using coal bottomash (CBA). IOP Conference Series: Earth and Environmental Science, 476(1), 1-6.

Lee, C. L., H'ng, P. S., Paridah, M. T., Chin, K. L., Rashid, U., Maminski, M., \& Khoo, P. S. (2018). Production of bioadsorbent from phosphoric acid pretreated palm kernel shell and coconut shell by two-stage continuous physical activation via N2 and air. Royal Society Open Science, 5(12), 1-19. doi: https://doi. org/10.1098/rsos. 180775

Li, C., Gao, Y., Li, A., Zhang, L., Ji, G., Zhu, K., \& Wang, X. (2019). Synergistic effects of anionic surfactants on adsorption of norfloxacin by magnetic biochar derived from furfural residue. Environmental Pollution, 254, 1-8. doi: https://doi.org/10.1016/j.envpol.2019.113005

Machrouhi, A., Alilou, H., Farnane, M., El Hamidi, S., Sadiq, M., Abdennouri, M., ... \& Barka, N. (2019). Statistical optimization of activated carbon from Thapsia transtagana stems and dyes removal efficiency using central composite design. Journal of Science: Advanced Materials and Devices, 4(4), 544-553. doi: https://doi.org/10.1016/j.jsamd.2019.09.002

Mianowski, A., Owczarek, M., \& Marecka, A. (2007). Surface area of activated carbon determined by the iodine adsorption number. Energy Sources part A, 29(9), 839-850. doi: https://doi. org/10.1080/00908310500430901 
Ooi, C. H., Lee, T., Pung, S. Y., \& Yeoh, F. Y. (2015) Activated carbon fiber derived from single step carbonization-activation process. ASEAN Engineering Journal, 4(1), 40-50. doi: https://doi.org/10.11113/ aej.v4.15426

Ramakreshnan, L., Rajandra, A., Aghamohammadi, N., Fong, C. S., \& Nalatambi, S. (2020). A preliminary insight into the environmental awareness of community in the vicinity of batik manufacturing units in Kelantan, Malaysia. GeoJournal, 85, 1745-1753. doi: https://doi.org/10.1007/s10708-019-10046-w

Shokry, H., Elkady, M., \& Salama, E. (2020). Eco-friendly magnetic activated carbon nano-hybrid for facile oil spills separation. Scientific Reports, 10(1),1-17. doi: https://doi.org/10.1038/s41598-020-67231-y

Suresh K. P., Prot, T., Korving, L., Keesman, K. J., Dugulan, I., van Loosdrecht, M. C. M., \& Witkamp, G. J. (2017). Effect of pore size distribution on iron oxide coated granular activated carbons for phosphate adsorption - Importance of mesopores. Chemical Engineering Journal, 326, 231-239. doi: https:/doi. org/10.1016/j.cej.2017.05.147

Vyavahare, G., Jadhav, P., Jadhav, J., Patil, R., Aware, C., Patil, D., .. \& Gurav, R. (2019). Strategies for crystal violet dye sorption on biochar derived from mango leaves and evaluation of residual dye toxicity. Journal of Cleaner Production, 207, 296-305. doi: https://doi.org/10.1016/j.jclepro.2018.09.193

Wang, Z., Rorvik, S., Ratvik, A. P., \& Grande, T. (2017). Formation of carbon build-up on the flue wall of anode baking furnace. In A. P. Ratvik (Ed.), Light Metals 2017 (pp. 1265-1274). Cham, Switzerland: Springer. doi: https://doi.org/10.1007/978-3-319-51541-0_151

Yang, Z., Ning, H. L., Jia, H., Li, Y., Meng, Z., \& Chen, Z. (2020) Preparation of porous composite materials with semi-coke based activated carbon doped with graphene oxide. IOP Conference Series: Material Science Engineering, 729(1), 1-5.

Yao, Y., Gao, B., Wu, F., Zhang, C., \&Yang, L. (2015). Engineered biochar from biofuel residue: Characterization and its silver removal potential. ACS Applied Material International, 7(19), 10634-10640. doi: https:// doi.org/10.1021/acsami.5b03131 